\title{
Narcoestética en Chile: El lenguaje corporal y los imaginarios visuales y culturales de estudiantes vulnerables de un liceo en Santiago
}

\section{Artículo de investigación}

Agradecimientos: Agradecemos principalmente a la generación de jóvenes estudiantes vulnerados, excluidos y estigmatizados del Liceo №5 de la comuna de Macul en Santiago de Chile. La inclusión es parte de un proceso que debe mirar la diversidad como el motor de un nuevo orden social. Por eso, la naturaleza de este artículo es dar a conocer una investigación, sobre la apropiación cultural de la narcoestética en jóvenes estudiantes y como esta afecta sus imaginarios.

\section{(c) (1)}

https://creativecommons.org/licenses/by/4.0/deed.es

\section{Rodrigo Andrés Aravena Otárola}

Universidad Central de Chile

aravenaotarola@gmail.com

\section{Mario Edgardo González Berríos}

Universidad Central de Chile

berrios.gonzalez@gmail.com

\section{Rubén Ignacio Dittus Benavente}

Universidad Central de Chile

ruben.dittus@ucentral.cl

\section{Eliana Verónica Romo López}

Universidad Central de Chile

eromo@ucentral.cl

Recibido el: 26/06/2020

Aceptado el: 25/08/2020

Cómo citar este artículo: Aravena Otálora, R. A., González Berríos, M. E., Dittus Benavente, R. I. y Romo López, E. V. (2021). Narcoestética en Chile: El lenguaje corporal y los imaginarios visuales y culturales de estudiantes vulnerables de un liceo en Santiago. Calle 14: revista de investigación en el campo del arte. 16(30), pp. 236-251. https://doi.org/10.14483/21450706.18299 


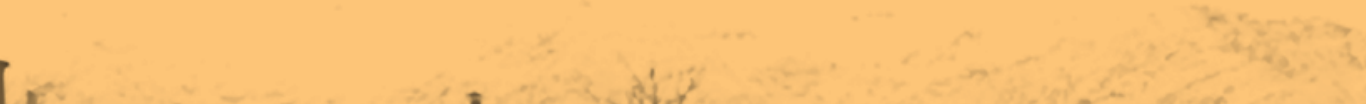

$\frac{\mathrm{h}}{1-T}$

भim

$120 \times 1$

maras a

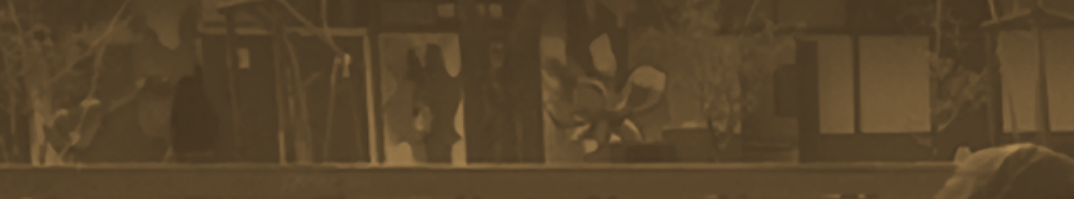

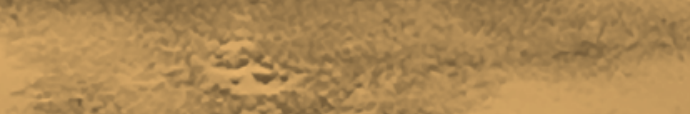

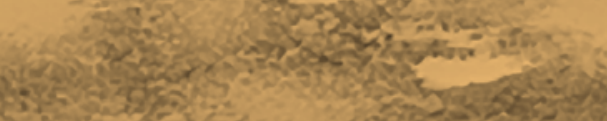

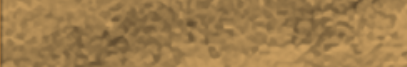

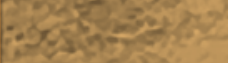

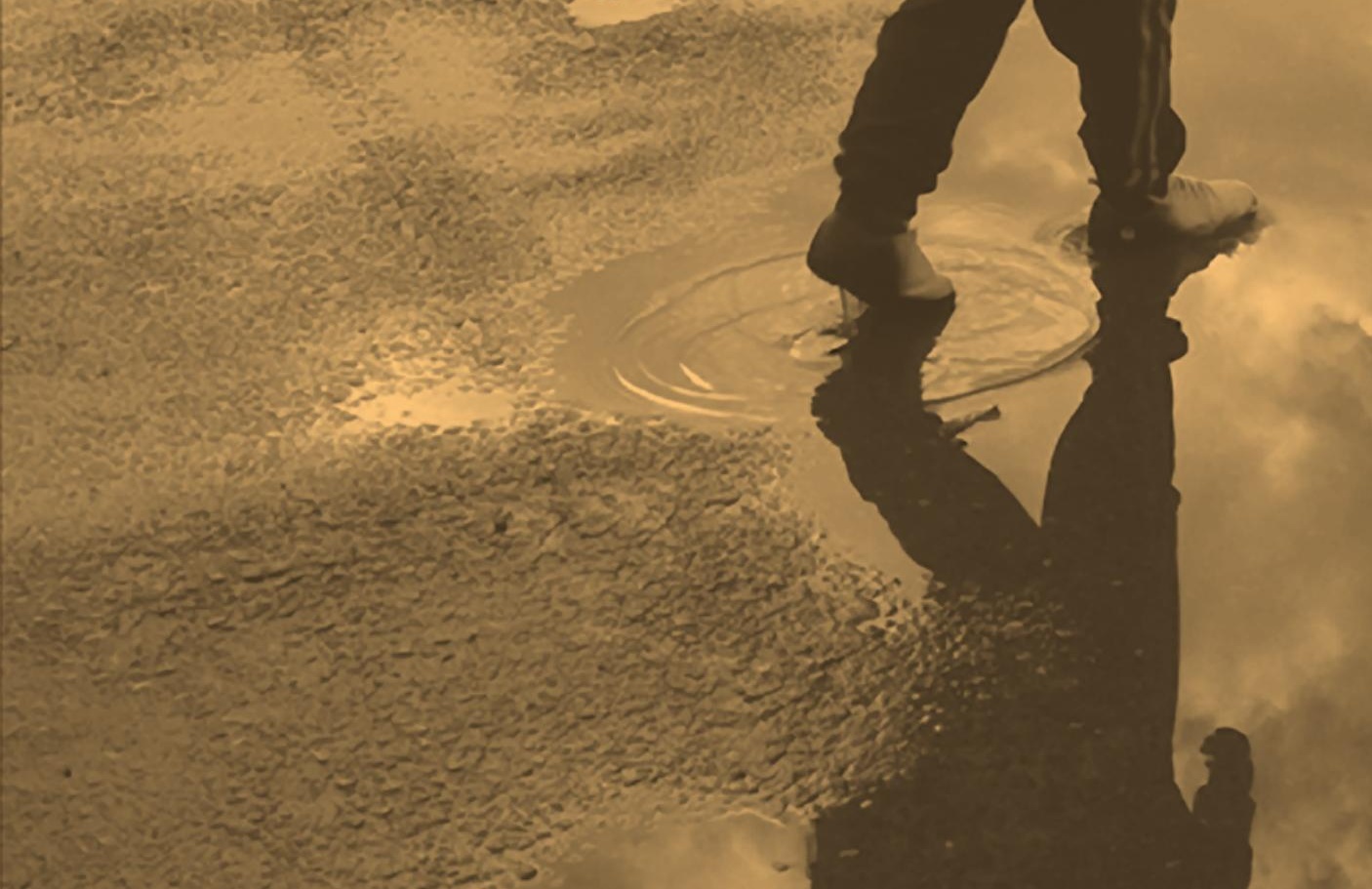


Narcoestética en Chile: El lenguaje corporal y los imaginarios visuales y culturales de estudiantes

vulnerables de un liceo en Santiago

\title{
Resumen
}

Objetivo: Describir e interpretar las percepciones de un grupo de estudiantes de secundaria, sus docentes y expertos escogidos, respecto a la influencia de la narcoestética como lenguaje corporal, y cómo esta afecta sus imaginarios visuales y culturales. Metodología: Se realizaron entrevistas previamente aprobadas entre los meses de junio y agosto de 2020. En esta microetnografía de corte cualitativo constructivista, se entrevistaron a 12 estudiantes de grados $1^{\circ}$ y $3^{\circ}$ de educación media y a cuatro de sus profesores, todos del mismo liceo de Santiago de Chile, más un asistente social, una psicóloga y una antropóloga como expertos. Resultados: Los estudiantes percibieron la narcoestética como un fenómeno social y colectivo donde son reproducidos y apropiados los imaginarios visuales y culturales producto de las culturas híbridas que luchan por descolonizarse del poder hegemónico que las margina. Conclusiones: El cuerpo es usado como un lenguaje que se hace político buscando emigrar constantemente de las fronteras simbólicas que lo someten.

\section{Palabras claves}

Cuerpo; frontera simbólica; hibridez; imaginarios; narcoestética

\section{Narco-aesthetics in Chile: Body language and visual and cultural imaginaries of vulnerable students \\ from a high school in Santiagd}

\begin{abstract}
Objective: To describe and interpret the perceptions of a group of high school students, their teachers and chosen experts, regarding the influence of narco-aesthetics as body language, and how it affects their visual and cultural imageries. Methodology: Previously approved interviews were conducted between June and August 2020. In this constructivist and qualitative microethnography, 12 students from grades 1 and 3 were interviewed, and four of their teachers, all from the same high school in Santiago de Chile, plus a social worker, a psychologist and an anthropologist as experts. Results: The students perceived narco-aesthetics as a social and collective phenomenon where visual and cultural imaginaries are reproduced and appropriated as a product of hybrid cultures that struggle to decolonize themselves from the hegemonic power that marginalizes them. Conclusions: The body is used as a language that becomes political, seeking to constantly emigrate from the symbolic borders that subject it.
\end{abstract}

\section{Keywords}

Body; symbolic border; hybridity; imaginary; narco-aesthetics

Narco-esthétique au Chili : Langage corporel et imaginaires visuels et culturels d'élèves vulnérables d'un lycée de Santiago

\section{Résumé}

Objectif : Décrire et interpréter les perceptions d'un groupe d'élèves du secondaire, de leurs enseignants et d'experts choisis, concernant l'influence de la narco-esthétique comme langage corporel, et comment elle affecte leurs imaginaires visuelles et culturelles. Méthodologie : Des entretiens préalablement approuvés ont été menés entre juin et août 2020. Dans cette microethnographie constructiviste et qualitative, 12 élèves de 1re et 3e années ont été interrogés, aussi que quatre de leurs enseignants, tous du même lycée de Santiago du Chili, plus un travailleur social, un psychologue et un anthropologue comme experts. Résultats : Les étudiants ont perçu la narco-esthétique comme un phénomène social et collectif où les imaginaires visuels et culturels sont reproduits et appropriés comme le produit de cultures hybrides qui luttent pour se décoloniser du pouvoir hégémonique qui les marginalise. Conclusions : Le corps est utilisé 
comme un langage qui devient politique, cherchant à constamment émigrer des frontières symboliques qui le soumettent.

\title{
Mots clés
}

Corps ; frontière symbolique ; hybridité ; imaginaire ; narco-esthétique

Narco-estética no Chile: A linguagem corporal e os imaginários visuais e culturais de estudantes vulneráveis de um liceu em Santiago

\section{Resumo}

Objetivo: Descrever e interpretar as percepções de um grupo de estudantes secundários, seus docentes e expertos, em relação a influência da narco-estética como linguagem corporal e como afeta seus imaginários visuais e culturais. Metodogia: Se realizaram entrevistas previamente aprovadas entre os meses de Junho e Agosto. Nesta micro etnografia qualitativa construtivista, se entrevistaram 12 estudantes do $1^{\circ}$ e $3^{\circ}$ ano do ensino médio e 4 de seus professores de um Liceu em Santigo do Chile, mais um assistente social, uma psicóloga e uma antropóloga como experts. Resultados: Os estudantes perceberam a narco-estética como um fenômeno social e coletivo onde são reproduzidos e apropriados os imaginários visuais e culturais, produto das culturas hibridas que lutam por descolonizar-se do poder hegemônico que os marginaliza. Conclusões: O corpo é usado como uma linguagem que faz política buscando emigrar constantemente das fronteiras simbólicas que o submetem.

\section{Palavras chave}

Corpo; fronteira simbólica; hibridez; imaginários; narco-estética

\author{
Maillallachiska \\ Munanaku parlangapa: tapuchiskakunata sug chunga iskai iachakunakuska, iachachidur kunata \\ imamika paikunamanda llapa kulkimanda rimai, llakispa kawanaku kunaurakausaita. \\ Imasam rurankuna tapuchi kawariskakuna kai killakunapi Junio, Agosto, mailla , mailla \\ iachachidurkuna ninaku chasallata iachachidur Liceo Santiago de Chile sutipi, chillapi tandariska \\ iskai warkuna, sumaglla kawaspa ñugpasinama apachingapa, ima rurangapa: llukanchi nukanchi \\ kikin munarispa sugsinama munarispa llalinga.
}

\section{Rimangapa Ministidukuna}

Nukanchi kikin; atun Ilagta tukuriskapi ima churaska; Ilawar; Ilakii; Ilakichinakui; iuiari; ruraikuata kulkiwa apadur 
"Mi cuerpo es como la Ciudad del Sol: no tiene lugar, pero a partir de él surgen e irradian todos los lugares posibles, reales o utópicos" (Foucault, 1966)

\section{Introducción}

Este estudio busca extender las investigaciones que vinculan la narcocultura y la narcoestética con las transformaciones sociales en Chile, del sociólogo Rodrigo Ganter Solis (2016) y el Doctor en Letras Danilo Santos (2016), ambos profesores de universidades chilenas. Así, el estudio abarca una mirada que trasciende la relación de la violencia y las formas simbólicas propias del tráfico de drogas. Al hablar de narcocultura y narcoestética generalmente se hace un reduccionismo metonímico. Esto es, tomar la parte por el todo, y esta parte no deja ver las miles de posibilidades que emergen de los cambios sociales. Sobre todo en culturas tan híbridas como las actuales. En el proceso de globalización que vivimos, debemos sumar además las mezclas generadas por la industria cultural, que se vale de los flujos e interacciones que debilitan las fronteras. Así, se propicia el concepto de hibridación, que es referido por Néstor García Canclini de la siguiente forma “Entiendo por hibridación procesos socioculturales en los que estructuras o prácticas discretas, que existían en forma separada, se combinan para generar nuevas estructuras, objetos y prácticas" (García Canclini, 2003).

Bajo esta mirada, hemos tomado las percepciones de estudiantes, sus profesores y algunos expertos (asistente social, antropóloga y psicóloga) para ver como impactan estas subculturas en sus imaginarios y representaciones. Además, observar cómo se van construyendo las diferentes identidades culturales que emergen en los intersticios ${ }^{1}$ y desplazamientos hacia una transformación social.

\section{Método}

El procedimiento empleado corresponde a una micro etnografía o estudio de casos. Realizado en un liceo vulnerable de una comuna periférica en Santiago de Chile y donde se empleó un enfoque paradigmático cualitativo constructivista. De acuerdo con los procedimientos más comunes utilizados para la codificación y

1 Hendidura o espacio, por lo común pequeño, que media entre dos cuerpos o entre dos partes de un mismo cuerpo (Real academia, 1970) análisis de datos cualitativos, es posible considerar como base del análisis de contenido cualitativo, las propuestas de Buendía (1999) y de Strauss y Corbin (2002). Estos modelos, altamente coincidentes, nos permiten sistematizar lo dicho en las entrevistas y cuestionarios de preguntas abiertas o en observaciones de corte etnográfico.

Las preguntas de la entrevista se ordenaron por categorías, textualidades, categorías emergentes y frecuencias. Se realizaron todas las entrevistas en un periodo de tres meses. Posteriormente estas fueron transcritas y transformadas en matrices abiertas, tal como se presenta en el gráfico 1. Para cautelar el rigor científico fueron auditadas por investigadores pares para asegurar el rigor de confirmabilidad. Se analizaron dos escenarios dentro de un mismo liceo: un escenario con estudiantes secundarios de $1^{\circ}$ medio y otro con $3^{\circ}$ medio. La triangulación de las textualidades, de los estudiantes, los profesores y los expertos generó dos matrices axiales, una para cada escenario. Así, se logró el criterio de rigor de la consistencia. Es decir, analizar de qué manera la información entregada por los sujetos tenía elementos comunes entre si. Las matrices axiales se triangularon obteniendo una matriz selectiva, que al ser analizada nos permitió ver qué categorías se transferían de un escenario al otro que nos permitían explicar el fenómeno en términos más generales, obteniendo como resultado 8 categorías emergentes que se mostraran a continuación:

\section{Resultados Gustos y estilos estéticos}

Ahora bien, el gusto de cada estudiante define su estilo estético y ello está vinculado a la aceptación y validación social. En esta subcategoría los expertos manifestaron que había una relación entre el estilo del vestuario con el nivel socioeconómico. La experta $(E x 2)^{2}$ entrevistada opina "Las clases sociales determinan como nos vestimos". Cada grupo usa una estética específica que los identifica, mediado por la búsqueda de pertenencia, el estudiante $(E 5)^{3}$ responde "La sociedad hace que te quieras ver bien para que seas aceptado entre la gente, eso es lo que hace también la internet". Para ellos no es relevante la situación económica o lo que les ofrece el mercado, ya que la cultura a la que pertenecen es totalmente híbrida. Esto también se traslada a sus imaginarios y a la forma en que se apropian de ellos. Por lo cual, cada estilo es una mezcla que tiene múltiples referentes, pero que están de acuerdo con su forma de sentir

2 Psicóloga, Santiago, junio 23,2019

3 Estudiante de $3^{\circ}$ medio, Santiago, agosto 12, 2019 


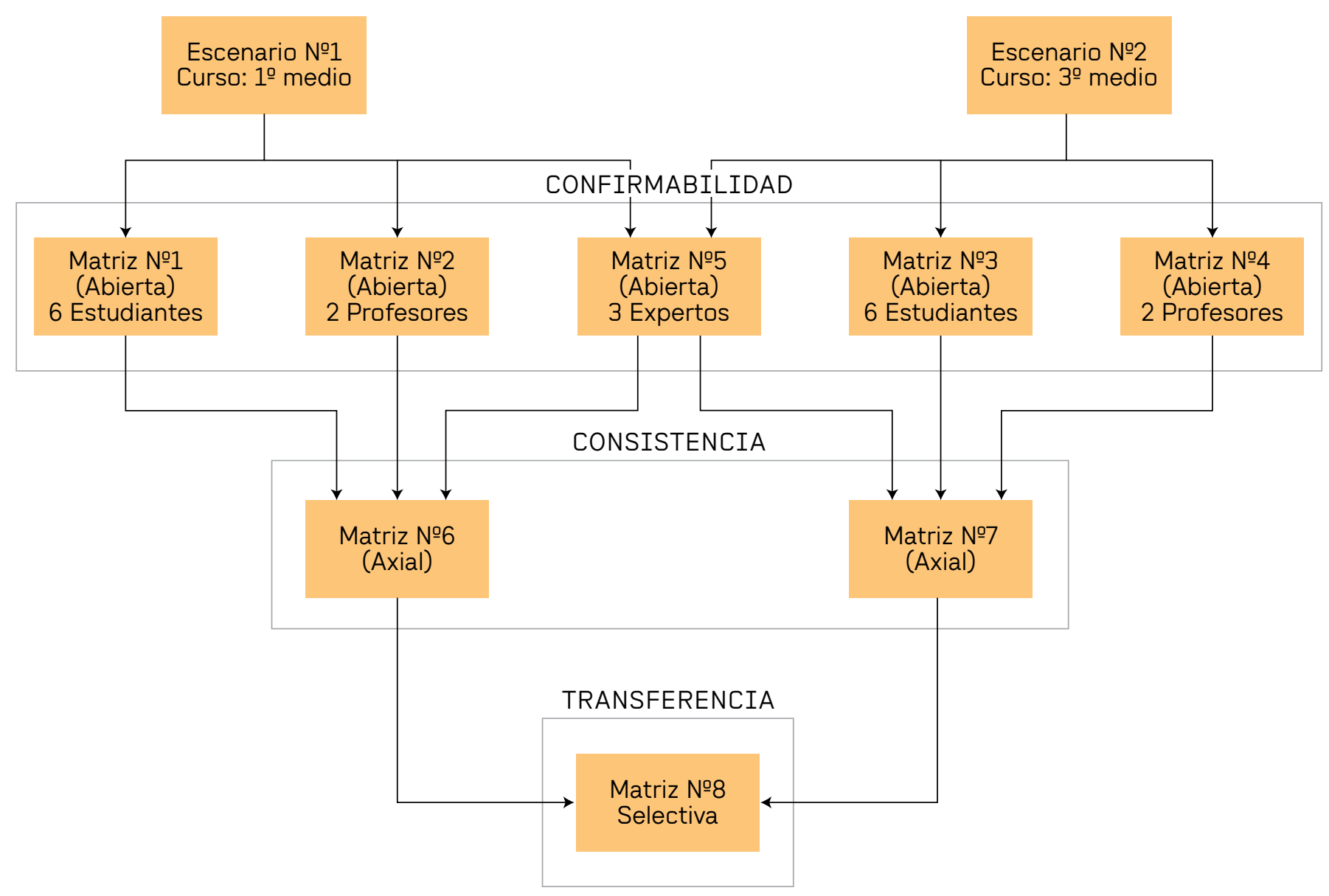

Esquema 1. Metodología. Creación propia.

en cuanto a lo individual y de identificarse en lo social. El tema del gusto ha sido estudiado por Immanuel Kant quien nos dice:

Para decidir si algo es bello o no, referimos la representación, no mediante el entendimiento al objeto para el conocimiento, sino, mediante la imaginación (unida quizá con el entendimiento), al sujeto y al sentimiento de placer o de dolor del mismo. El juicio de gusto no es, pues, un juicio de conocimiento; por tanto, no es lógico, sino estético, entendiendo por esto aquel cuya base determinante no puede ser más que subjetiva (Kant, 1989: p.101)

Según Kant la reflexión estética está condicionada por la sensibilidad del sujeto humano. Esta es una condición natural que está en concordancia con su moral. Por lo tanto, el juicio estético también se hace juicio ético. Actualmente en el marco de la globalización el gusto estético ha cambiado en su definición; Carlos Fajardo (2014), nos plantea que:
El gusto es, tanto un fenómeno individual —cada uno se configura su gusto-, como un fenómeno colectivo, social, histórico, educable. Pero, aunque inmerso en las determinaciones de lo histórico, el gusto también puede provocar la ruptura con lo histórico; invita a traspasar umbrales, vislumbrar otras orillas, visionar lo invisible, sentir lo sublime. (Fajardo, 2014: p.61)

A este fenómeno se le llama intersubjetividad, un relativismo que va mutando, fluyendo, cambiando. $Y$ en este tránsito se mueven los y las jóvenes desde la dependencia hacia la independencia y viceversa, enriqueciéndose o ampliándose el gusto. Dada la cantidad de textualidades que aluden al gusto y los estilos que los y las jóvenes van adoptando, parece de gran relevancia considerar este aspecto en la búsqueda de comprensión del comportamiento de ellas y ellos, de los valores culturales visuales y corporales y las formas en que se produce su cambio cultural y creativo. 


\section{Narcocultura y consumismo}

En esta subcategoría la profesora entrevistada (P3) ${ }^{4}$ mencionó "Finalmente el narcotráfico está dentro del sistema capitalista que fomenta el poseer cosas materiales, donde el individuo se transforma también en un bien de consumo". Se observa una estrecha relación entre capitalismo y narcotráfico, que obedece a una subcultura que deriva del capitalismo, imponiendo su lógica del consumismo y en donde lo llamado 'narco' se ve como un producto más a adquirir, sin mediar un cuestionamiento, un pensamiento crítico. Parece no haber una conciencia que cuestione su origen, o si este es ilícito o legal. La estudiante $(E 6)^{5}$ responde "si te gusta ese estilo, tienes que hacerlo no más, o sea, independiente si está imitando quizás a un narco". El modelo socioeconómico imperante los lleva a no discriminar entre productos a consumir y se plantean por tanto sin ética, sin valores claros. Lo llamativo, es que vestirse a la moda (y en estos casos asumir la moda narco) se asume rápidamente, sin cuestionamiento. Así, el sistema logra su objetivo. El cual es hacer que el producto llegue a popularizarse lo más pronto posible en el mercado.

También, debemos considerar que la narcocultura es un fenómeno transcultural que determina como se coloniza un espacio y como se determinan formas de vivir en ese espacio. En efecto, en palabras de Rodrigo Ganter la narcocultura sería:

[...] un estilo de vida transfronterizo expresado en hábitos, costumbres, prácticas concretas, estéticas, modos de construir lo corporal, significados, imaginarios sociales y valores como: la violencia y el poder, la lealtad y el silencio, el ajuste de cuentas, la fe en una entidad superior extraterrenal, la familia y el clan, el hedonismo y lo festivo, el coraje, el paternalismo clientelar, el lujo y la ostentación, el machismo, etc. (Ganter, 2016: p. 291)

En los estudiantes se encuentra más bien instalada, la manifestación estética de la narcocultura apropiándose de sus formas simbólicas, las cuales se van hibridando en esta subcultura. La Experta (Ex2) comenta: "La narcoestética está dentro de la narcocultura [...] tiene que ver con cómo me gano la vida, con ideología". De esta manera, el tránsito hacia la narcocultura obedece a los patrones que el capitalismo impuso. Al respecto, José Valenzuela (2014), nos dice: "poco

4 Profesora $3^{\circ}$ medio, Santiago, julio 10, 2019

5 Estudiante de $3^{\circ}$ medio, Santiago, junio 25, 2019 importa la forma mediante la cual se obtienen esos bienes, en una sociedad que presenta varios discursos para el triunfo. En este escenario, los narcotraficantes son uno de los ejemplos límites del consumo y la presunción" (Valenzuela, 2002: p. 154)

\section{Naturalización de uso de drogas fuera del liceo}

En esta subcategoría los estudiantes percibieron que había que respetar la prohibición de drogas dentro del liceo. Sin embargo, fuera de éste, el consumo se naturaliza. Las respuestas dejan entrever que el consumo es casi cotidiano y no restringido, la estudiante (E6) añade "Si quieres drogarte y tomar nadie te lo puede prohibir, eso lo puedes hacer afuera, no dentro del liceo". Además, los expertos ven que hay una relación que aún no se ha zanjado en las leyes chilenas que relaciona el consumo de drogas y la legalidad. En la entrevista el experto (Ex1)6 opinó que: "Hay una relación entre el consumo versus fenómeno del tráfico de drogas". Si bien existen normas de prohibición dentro de los establecimientos, siempre está la amenaza del microtráfico en las cercanías del liceo, como también dentro de él. Lo anterior, según investigaciones de SENDA, (2018) (Servicio Nacional para la Prevención y Rehabilitación del Consumo de Drogas y Alcohol). Allí, se encuestaron jóvenes de varios colegios y liceos a lo largo de todo Chile.

Los resultados principales manifestaron que hay un aumento significativo en cuanto al tráfico de drogas en los alrededores del colegio, de un $62,8 \%$ en 2015 a un $64,7 \%$ en 2017. También, las respuestas a si se ha visto consumo de drogas dentro del colegio subieron de un 49,9\% en 2015 a un 53,4\% en 2017. La mayoría de los estudiantes encuestados consume preferentemente marihuana (sativa) con distintos propósitos desde los recreativos, usados en tiempos de ocio, hasta relacionales, usándose para sociabilizar en distintos grupos. Todas estas variantes de estudio nos muestran un panorama global de los colegios particulares subvencionados en la Región Metropolitana en cuanto al consumo de droga, particularmente marihuana, tanto en $1^{\circ}$ medio como en $3^{\circ}$ medio. Es durante esta etapa de la vida que el adolescente va conociendo el mundo más allá de las fronteras impuestas por los padres, donde experimentar y probar cosas nuevas es parte esencial en el desarrollo de su identidad y donde la sociabilización toma un rol importante en la validación y la pertenencia

6 Asistente social, Santiago, junio 7, 2019 


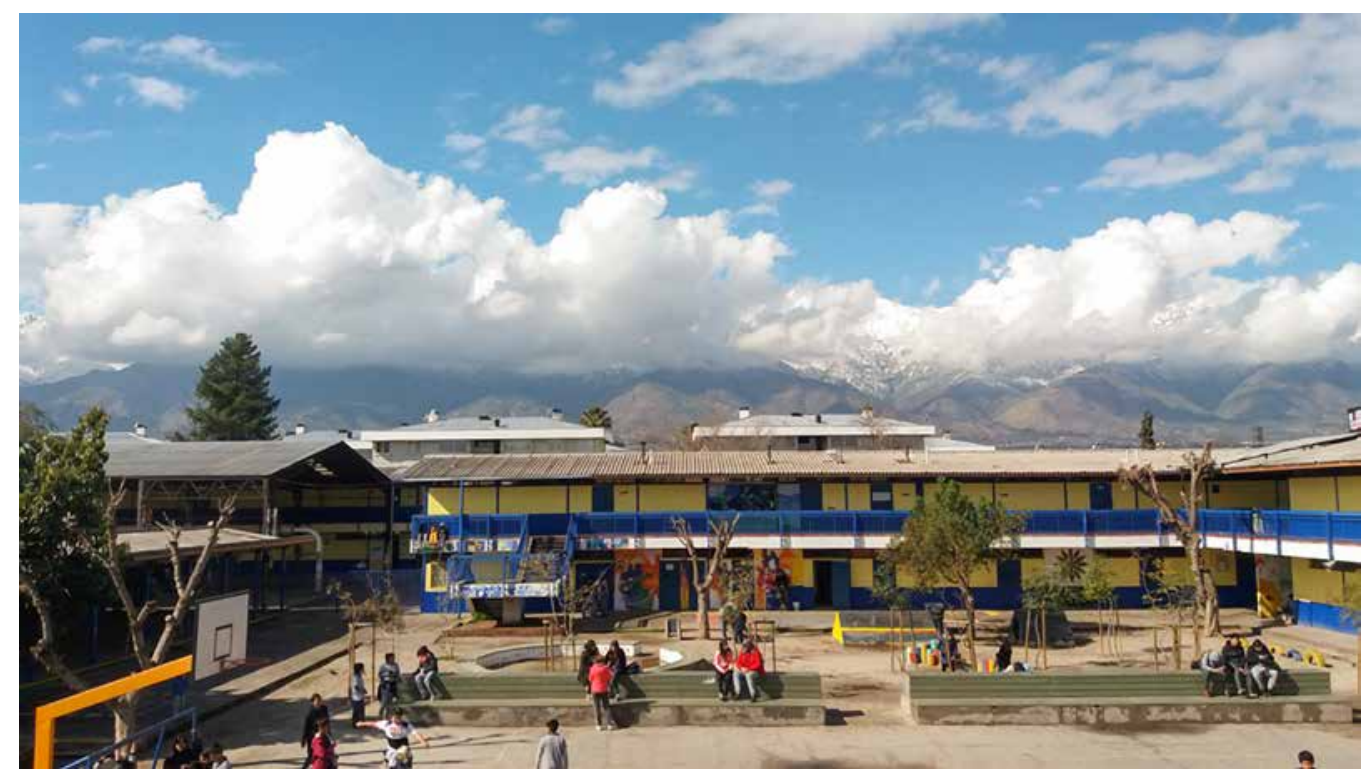

Trabajo de campo (2020). Fotografía: Mario González

que finalmente lo va construyendo como sujeto. En la subcategoría del análisis, referida a la naturalización del uso de droga, el estudio de SENDA parece confirmar esta idea; sobre todo cuando los padres parecen ir aceptando con mayor soltura el consumo de marihuana.

\section{Nociones de machismo y cosificación de la mujer}

Ahora bien, en esta subcategoría tanto estudiantes como profesores y expertos, en ambos escenarios, opinaron y percibieron la relación entre machismo y cosificación de la mujer. La profesora (P3) plantea: “La narcocultura, entiende que las relaciones humanas son de cosificación, en este caso se relaciona directamente con las mujeres, ellas hablan más bajo, no saben pelear". El estudiante (E2)7 comenta que "el machismo viene de antes que saliera el reggaetón, para que andamos con cosas si el rock and roll también hablaba de sexo, alcohol y drogas [...] tampoco son letras muy feministas que digamos, porque principalmente los que las hacían, eran hombres". Esta ha sido una categoría emergente que visualiza el machismo dentro de la narcocultura o aquel expuesto en la letra de canciones de música urbana tanto del reggaetón y el trap que escuchan los adolescentes. Además, demuestra que es considerado un fenómeno que emerge de mucho más atrás en la sociedad y que se ha ido reproduciendo históricamente hasta hoy. No debemos olvidar que la

$7 \quad$ Estudiante de $1^{\circ}$ medio, Santiago, mayo 28, 2019 figura de Dios de muchas culturas es la figura masculina del Padre. Octavio Paz (1981), expone esta construcción histórica del patriarcado:

En todas las civilizaciones la imagen del Dios Padre -apenas destrona a las divinidades femeninasse presenta como una figura ambivalente. Por una parte, ya sea Jehová, Dios Creador, o Zeus, rey de la creación, regulador cósmico, el Padre encarna el poder genérico, origen de la vida; por la otra es el principio anterior, el Uno, de donde todo nace y a donde todo desemboca. (p.33)

Las mujeres han ido ganando espacios desde el feminismo por la igualdad de derechos entre hombres y mujeres. Estamos ante uno de los momentos históricos del movimiento feminista, donde miles de voces se han sumado alrededor del planeta en contra del machismo, la violencia y de toda discriminación hacia ellas. La filósofa Elsa Dorlin (2009), nos plantea una mirada doble al fenómeno de interseccionalidad, que analiza cómo se produce y reproduce una sociedad desde la perspectiva de la dominación. Por un lado, está la perspectiva analítica, que ve desde diferentes ángulos las formas de discriminación; ya sean por sexo, raza o clase que interactúan entre sí dinámicamente. Por otro lado, está la perspectiva fenomenológica, la cual nos muestra que la dominación también es una forma de conducta que se proyecta en toda la sociedad.

La interseccionalidad, además, analiza dos puntos importantes: el primero tiene que ver con la 
discriminación de sexo ejercida sobre las mujeres. El segundo se relaciona con las estructuras sociales que no sufren discriminación ellas mismas, pero que se constituyen en la norma social que discrimina a las demás. En estas estructuras sociales encontramos por ejemplo la masculinidad, la heteronormalidad, el patriarcado, etc. Así, se investiga de dónde se producen y reproducen estas intersecciones de dominación, que se construyen históricamente y que generan discriminación hacia las mujeres. Desde el análisis de esta subcategoría, podemos hipotetizar que la discriminación y dominación patriarcal que afecta a las mujeres y a personas con identidades sexuales no heteronormadas, se sustenta en una cultura en la que el poder masculino es el dominante (Agamben, 1995).

Esta idea patriarcal, de acuerdo con Santos, se ve reforzada por las propuestas neoliberales, provenientes también de las epistemologías del norte y que nos llevan a considerar la producción como lo relevante para el sistema económico, para la riqueza material. Mientras que, la reproducción y el cuidado de los otros son vistos como poco 'productivos' en materia económica y por tanto inferiores. Así, la asociación de producción y hombre versus reproducción y mujer es histórica (Beauvoir, 1949).

\section{Diversidad social y convivencia}

Esta categoría emergente considera la diversidad social como una apertura a la diferencia tanto de género, clase o raza. Un nuevo mirar que ha fomentado una convivencia desde la diversidad. La experta (Ex2) señala "A los hombres les dicen, esto es masculino y a las mujeres esto es femenino y hoy en día se ha abierto esta mirada". El estudiante (E4) ${ }^{8}$ opina "Porque igual se puede estar mujer con mujer, hombre con hombre, ya no importa, es la decisión de cada uno". Teniendo en cuenta las perspectivas que tratan de equilibrar las desigualdades, Unesco (2005) se ha referido a la importancia de abordar y responder la diversidad de necesidades que tienen todos los estudiantes. El campo de la diversidad se entiende como un campo amplio, polisémico y controversial. Por esto, el desafío es lograr una educación inclusiva, equitativa y de calidad y un aprendizaje a lo largo de la vida para todos, como lo dice la declaración de Incheon (2015) ${ }^{9}$.

\footnotetext{
8 Estudiante de $1^{\circ}$ medio, Santiago, agosto 12, 2019

9 Incheon ciudad coreana donde aconteció el Foro Mundial sobre la Educación 2015. Cuyos acuerdos quedaron plasmados en la Declaración de Incheon para la Educación 2030
}

Desde la perspectiva de la diversidad y la convivencia hemos percibido una preocupación por fomentar la inclusión en espacios educativos vulnerables, y desde ahí construir una sociedad que respete esas diferencias, que no estigmatice más a los estudiantes. La palabra vulnerable viene del latín vulnerabilis, formada de vulnus (herida), y el sufijo -abilis (-able, indica posibilidad). Es decir, que puede ser herido (Etimológico, 2019). En este aspecto, debemos preguntarnos qué hacer para que las medidas estatales que buscan no discriminar, no se transformen en lo contrario, es decir no caer en la estigmatización, o cómo ayudar a no estigmatizar más, o herir más aún a los menos favorecidos (Castel, 2004).

Con respecto a esta misma problemática el profesor de psicología Gerardo Echeita (2013) nos dice:

El tener una sola respuesta a estos dilemas, desde lo técnico tampoco es la solución, dado que en el complejo mundo de las comunidades educativas, el mejor resultado para la inclusión está dado en dialogar, negociar y reconstruir significados pertinentes a cada lugar y momento, por lo que se deben fomentar modelos democráticos y participativos. (Echeita, 2013: p.5)

De esta manera, resulta fundamental abrirse a estas subculturas que se generan en nuestras comunidades, que son las que los y las jóvenes identifican como propias. Acogerlas y colaborar en su análisis crítico, sin menospreciarlas desde el inicio, parece ser una clave esencial.

\section{Agresividad, descontento social}

Por otra parte, en esta categoría emergente se relaciona la violencia con el descontento social. Se transforma en una categoría contingente en momentos que el país sufre una de las crisis más grandes postdictadura. El profesor (P4) ${ }^{10}$ dice que "la agresividad la veo como consecuencia del sistema. Vale decir, modelo capitalista, neoliberal". También, la experta (Ex2) entrevistada agrega: "yo creo que si hubiera una sociedad que a todos les ofreciera una vida digna no habría narcocultura". Además, el estudiante (E2) opina que "la violencia no lleva a nada, pero sí en algunos casos es la solución. Ya cuando no tienes nada más, ya no puedes hacer nada más, tienes que defenderte". 
En esta categoría emergente percibimos que, al parecer el origen de las desigualdades, que traen como consecuencia el descontento social, parten de un sistema hegemónico. Un sistema que se ha instalado desde antes del capitalismo, y que se ha configurado desde las culturas euro céntricas de occidente. El Sociólogo De Sousa Santos (2006) nos habla, de descolonizar los saberes para lograr una emancipación social a través de las epistemologías del Sur. Según este autor, tenemos dos tipos de razones indolentes interactuando dentro de lo que él llama 'la sociología de las ausencias'. La primera es la razón 'metonímica', figura de la teoría literaria, que significa tomar la parte por el todo. Esta problematiza las formas monoculturales, donde la experiencia y los saberes de los pueblos originarios o la de las poblaciones marginales van quedando por fuera y ausentes en la construcción social, es decir contrae el presente. La segunda es la razón 'proléptica', también figura literaria que significa conocer en el presente el futuro. Es decir, el futuro se expande. Santos nos explica que los países nunca salen del tercer mundo y que pese a su progreso y desarrollo siempre quedan atrás de las potencias económicas del primer mundo.

La razón indolente, entonces, tiene esta doble característica: en cuanto razón metonímica, contrae, disminuye el presente; en cuanto a razón proléptica, expande infinitamente el futuro. Y lo que les voy a proponer es una estrategia opuesta: Ampliar el presente y contraer el futuro. Ampliar el presente para incluir en él muchas más experiencias, y contraer el futuro para cuidarlo. (De Sousa Santos, 2006: p.21)

\section{Lenguaje corporal como expresión estética y de comunicación}

El cuerpo como soporte estético se transforma en un medio por el cual los estudiantes se comunican. El experto (Ex1) opina: "la corporalidad [...] tiene una influencia, vista desde lo estético claramente produce un efecto, sin necesidad de que yo diga nada". Podemos suponer que los propios estudiantes no están tan conscientes de cómo se visten. Sin embargo, hoy el cuerpo de ellos tiene más independencia del poder y control de los padres. Una estudiante (E6) ${ }^{11}$ opina: "yo creo que es sentirse más liberado, de que el cuerpo es de nosotros, es el derecho sobre el cuerpo de uno". Pero, tanto para profesores como los expertos es

11 Estudiante de $1^{\circ}$ medio, Santiago, agosto 12, 2019 evidente que su forma de verse es comunicacional. Lo corporal se desplaza al territorio político de los estudiantes no solo son productos culturales, más bien responden a ciertos estímulos culturales en los cuales confluyen y se visibilizan los fenómenos sociales. Según Foucault (2008), el cuerpo se desplaza en el terreno utópico que es un lugar fuera de todo lugar.

La máscara, el signo tatuado, el afeite, depositan sobre el cuerpo todo un lenguaje, todo un lenguaje enigmático, todo un lenguaje cifrado, secreto, sagrado, que invoca sobre ese mismo cuerpo la violencia del dios, la potencia sorda de lo sagrado o la vivacidad del deseo. (p.15)

Así mismo, la cultura juvenil heterogénea se ve enfrentada a la cultura escolar que trata de homogenizar no solo en los aprendizajes sino también en el territorio estético. La estudiante (E1) opina que "tener buen cuerpo y todo eso porque la sociedad ha optado a que una persona tiene que ser flaca, y bonita si no, no sirve, entonces yo creo que los jóvenes de hoy en día juzgan mucho eso". Llama la atención que la estudiante encuentra una forma de lenguaje corporal para ser escuchada en sus demandas sociales. El cuerpo se vuelve político y colectivo contra el Estado, que primero abusa de él y luego lo reprime violentamente. Estamos ante una situación que Agamben (1995) analiza desde el poder soberano impuesto por el Estado sobre los ciudadanos.

Así, vemos este fenómeno en tiempos de crisis sociales y para analizarlo nos tenemos que adentrar en el campo de la biopolítica, dónde percibimos una relación asimétrica entre el poder soberano y la independencia. En este caso el poder del Estado y los marginados de ese poder, condenados a una 'nuda vida'. Es decir, una vida desprovista de toda cualificación y de toda independencia. Es un prisionero del Estado que le impone y limita la forma de cómo vivir su vida. Por lo anterior, estas dinámicas sociales y políticas determinan que cierto grupo de individuos ligados al poder del Estado abuse de sus privilegios. Mientras que otros son desplazados, estigmatizados y vulnerados como sucede con los estudiantes en esta investigación. De esta manera, el sistema educativo va reproduciendo estas asimetrías aumentando las brechas y desigualdades, vulnerando no solo a los estudiantes, sino que a toda la comunidad.

Hoy la crisis social contextualiza el lenguaje corporal que sin una mirada de sentido se veía sin dirección. Ahora podemos ver toda esa carga simbólica estética, donde las vías normales de comunicación fueron 


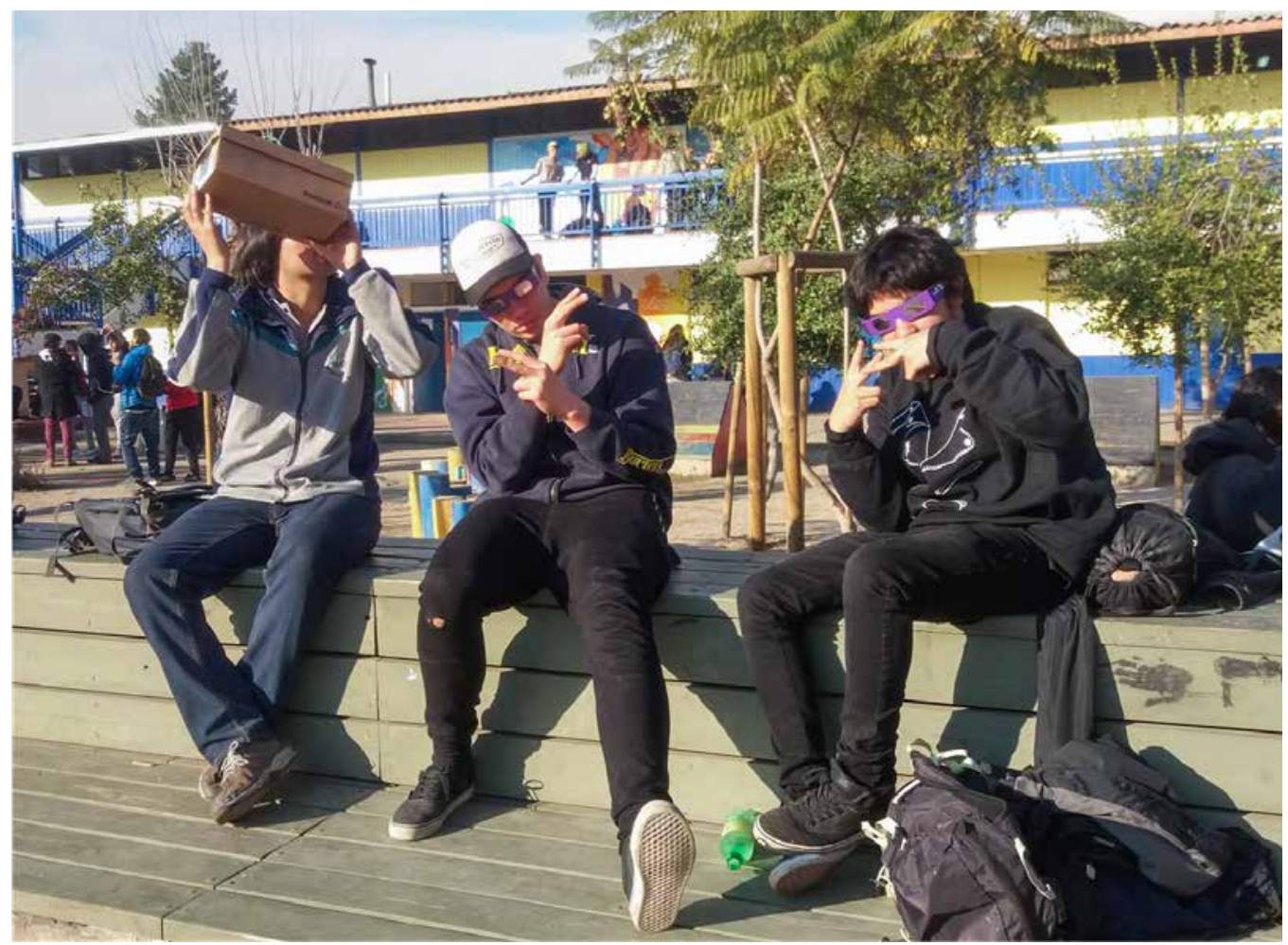

Trabajo de campo (2020). Fotografía: Mario González

negadas por la exclusión y la movilidad social detenida. En donde se originó otro lenguaje, posibilitando otras formas de expresión que lograron manifestarse en demanda de transformaciones sociales. En estas nuevas formas de expresión encontraron cabida las culturas híbridas, dónde además se encuentra la narcocultura. En ella los marginados se reinventan, se deconstruyen en demanda de un cambio social que los considere y no los segregue.

\section{Música y cultura urbana}

En esta categoría emergente, el profesor (P1)12 opina: "habían algunas formas en particular, muy cargadas de significados, que venían del extranjero [...] en el fondo eran gritos de reclamo de pobreza". Los estudiantes escuchan principalmente música de internet, recibiendo la influencia de estereotipos como sus ídolos y modas a seguir. Por esto, la estudiante (E1) ${ }^{13}$ opina que "Ios ídolos como que te dan cierta fuerza para poder seguir adelante, para luchar por tus sueños, porque hay muchos cantantes o ídolos que me gustan a mí, que vienen desde abajo y luchando solos han llegado a donde están, como que te dan un ejemplo de superación".

12 Profesor de $1^{\circ}$ medio, Santiago, junio 27, 2019

13 Estudiante de $3^{\circ}$ medio, Santiago, agosto 6, 2019
En adición a esto, el experto (ExI) menciona que "hay una necesidad también de expresar algo, que no se ha expresado nunca, que a lo mejor lo han vetado durante mucho tiempo, y que reventó de esta forma".

Ahora bien, la tecnología ha hecho que escuchar música se constituya en una de las principales características de los adolescentes actuales, quienes interactúan con sus teléfonos móviles gran parte del tiempo. El fenómeno de ubicuidad de la tecnología, en que la información está disponible en todas partes al mismo tiempo, ha traspasado los límites de sus viviendas y logrado hacer parte de la cultura urbana adolescente. Aquí la música popular adquiere otro estatus, como característica está la identificación de los adolescentes con lo que narran las letras de las canciones. En donde se presentan experiencias de vida similares con las cuales se sienten identificados. En ella las epistemologías del sur cobran fuerza. La música urbana o música popular se hace masiva y comercial, es ahí donde existe un peligro, ya que la globalización con su industria cultural transforma el sentido de la música convirtiéndola en un producto fetiche, hedonista y machista. Theodor Adorno (2009) escribe sobre el carácter de mercancía de la música.

Pues la totalidad de la vida musical del presente está dominada por la forma de la mercancía: se han erradicado los últimos residuos precapitalistas. La 
música, con todos los atributos de lo Estético y de lo Sublime que le son otorgados generosamente, está en América esencialmente al servicio de los anuncios de las mercancías que han de adquirirse para poder oír música. (Adorno, 2009: p.13)

Los estudiantes aún con este bombardeo mediático también escuchan música con el sentido y fuerte crítica social que dejó la generación anterior; la cual vivió en la dictadura militar. Es música que se mantiene aún hoy, como himnos de las luchas sociales actuales, aun no zanjadas. En este escenario se va construyendo un discurso de prácticas, costumbres e imaginarios propios de la cultura latina, que busca emancipación de la hegemonía. Que desplazan los saberes, descolonizándolos.

Las manifestaciones musicales emergen en estos espacios liminales, planteando una fuerte crítica social. Se presenta en el hip hop y el rap, que escuchan mucho los estudiantes en las poblaciones y que además cantan en los pasillos del liceo y en las calles. También escriben y van improvisando letras que les permiten expresar el descontento social y la exclusión del sistema, entre los más escuchados está el rapero Andi Portavoz que manifiesta en sus letras las desigualdades sociales del país.

Ese Chile al que definen de clase media, pero tienen las medias deudas que los afligen y los asedian, el Chile de mis iguales y los tuyos, que no salen en las páginas sociales de "El Mercurio", no tienen estatuas y no tienen calles principales, y no son grandes personajes en las putas historias oficiales. (Portavoz, 2013)

Las letras de estas canciones tienen aún más sentido en el estallido social del 18 de octubre del 2019, el clamor del pueblo por la dignidad, se hace una sola voz, frente a los poderosos. "Sus discursos de unidad nacional, son solo eso, discursos, porque otra es la realidad. Vivimos en una sociedad segregá, y no es casualidad, siempre lo quiso así la clase acomodá" (Portavoz, 2013)

En las letras del rap aparece y vuelve a sonar el mapudungun en las nuevas generaciones la lengua originaria del pueblo mapuche, descolonizando la cultura hegemónica. El rapero Luanko en la canción witxapaiñ, expresa:

Todavía estoy aprendiendo, yo soy un aprendiz, yo nací en la ciudad, pero desperté con fuerza. Que siga nuestro caminar y antigua vida, por eso están por aquí nuestros ancestros. Defenderemos nuestro conocimiento, el vivir correcto, lo haremos estaremos de pie en todas las tierras. Vemos sus mentiras, por eso lucharemos, igritaremos!14

(Luanko, 2018)

\section{Conclusiones}

Concluimos según los resultados obtenidos del análisis de estas categorías que la narcoestética es una estética híbrida, adoptada por los adolescentes como parte de la actual cultura. Esta funciona como un crisol que mezcla, transforma y reproduce diferentes imaginarios estéticos, que se adoptan del incesante bombardeo de imágenes y referentes que consumen principalmente en las redes de internet. En un mundo cada vez más globalizado las fronteras territoriales y culturales se han abierto con las tecnologías permitiendo el libre acceso a la información, la cual es adoptada, transformada y mezclada constantemente. Así, en la lucha entre la individuación y la colectividad; entre la homogeneidad y la heterogeneidad; las luchas de poder y las fronteras simbólicas de exclusión, provocadas por el sistema hegemónico y la narcocultura, los adolescentes han encontrado, un intersticio. Que se da desde las epistemologías del Su. Estas han emergido rizomáticamente en las subculturas urbanas, para expresarse y manifestarse en contra del sistema que los margina y estigmatiza.

La sociedad híbrida estudiada por García Canclini (1990) elabora un análisis de la forma en que la cultura se mueve a través de la modernidad, produciendo y reproduciendo desigualdades. En este estudio vemos como los estudiantes se mueven en este mundo cada vez más globalizado que recibe el aporte de varias culturas que se van mezclando. En la estética de los jóvenes confluyen zapatillas, poleras, gorros y polerones que usan basquetbolistas norteamericanos, cortes de pelo de futbolistas en el caso de los hombres, mientras las mujeres se tiñen el pelo de diferentes colores con influencia asiática. Todos usan celulares la mayor parte del tiempo, escuchan música latina como reggaetón y trap. También escuchan y cantan rap, es aquí donde también están sus ídolos, que se transforman en iconos estéticos. La mayor parte de ellos habla en 'coa', una

\footnotetext{
14 Letra original de la canción Witxapaiñ (Estamos de pie), primera estrofa cantada por Luako "Petu chillkatuken inche, chillkatufegen choyugen warria mew, welu newentu txepen. Amulepe taiñ txekan, kuifike mogen,feymu ta müley fawpüle, taiñ kuifikecheyem Ingkakeiñ, taiñ kimün nor mogen, femayaiñ, witxapaiñ fill püle mapu azkintuiñ, tamün koila zugu feymu weichatuaiñ, wirakeiñ!"
} 
jerga o dialecto usado en las cárceles de Santiago. Sus cuerpos hoy están decorados con tatuajes que copian de internet, también se hacen perforaciones, piercing en diferentes partes del rostro y cuerpo, muchos se hacen expansiones en los lóbulos de las orejas. Si miramos bien el origen de estas formas estéticas, encontraremos un denominador común. La mayoría de estos ídolos son personas que provienen de un sector de la sociedad en donde han sido desplazados y excluidos, el basquetbolista y el futbolista provienen de barrios marginales, al igual que los cantantes que escuchan. Los estudiantes vulnerables elaboran sus propios referentes, a partir de quienes puedan resistir y alzarse sobre las injusticias sociales. Estos se transforman en el imaginario de la población adolescente, que redirige su horizonte utópico pese a la gran barrera de desigualdades que tendrá que enfrentar hoy y en el futuro. García Canclini dice al respecto.

En medio de estas tensiones se constituyen las relaciones complejas, nada esquemáticas, entre lo hegemónico y lo subalterno, lo incluido y lo excluido. Ésta es una de las causas por las que la modernidad implica tanto procesos de segregación como de hibridación entre los diversos sectores sociales y sus sistemas simbólicos. (1990, p.40)

Los estudiantes manifiestan en este estudio, que en mayor porcentaje es a través de las redes sociales donde ellos construyen sus imaginarios estéticos, una forma transcultural de hacer propio, lo que perciben en otros países. En esta cultura mediatizada, los referentes de la cultura popular son consumidos y se van mezclando, con los imaginarios locales, “Por extensión, es posible pensar que lo popular se constituye en procesos híbridos y complejos, usando como signos de identificación elementos procedentes de diversas clases y naciones" (García Canclini, 1990, p. 202).

En las culturas híbridas emergen las otras culturas, invisibilizadas ante el poder hegemónico del sistema, es aquí donde toman valor. Ya que la cultura es un conjunto de prácticas sociales, que se desplazan en el tiempo y el territorio. Hay un rescate de las costumbres que se han perdido con la imposición de un sistema individualista, pero que resisten y vuelven a emerger fusionándose a otras manifestaciones, consideradas menores. Por ejemplo, la música popular o la artesanía:

[...] En relación con otras artes: las artesanías migran del campo a la ciudad; las películas, los videos y canciones que narran acontecimientos de un pueblo son intercambiados con otros. Así las culturas pierden la relación exclusiva con su territorio, pero ganan en comunicación y conocimiento. (García Canclini, 1990, p. 326)

La lucha de clases en que están sumergidos los estudiantes los hace revelarse frente a un sistema totalizador que les impone una forma de vivir. Pero la rebeldía propia de los adolescente logra aun así manifestarse en los intersticios que las fronteras simbólicas pretenden someter. Esta sale a relucir en las marchas actuales. Es la potencia de los jóvenes desplazados por el sistema en su legítima manera de expresarse, ante un poder que los sobrepasa. Entonces se recurre a la metáfora que aparece en el humor gráfico en las redes, grafitis, música, memes, collages, murgas y pancartas, junto a los carnavales que colectivizan a la sociedad segregada y marginada.

Ante la imposibilidad de construir un orden distinto, erigimos en los mitos, la literatura y las historietas desafíos enmascarados. La lucha entre clases o entre etnias es, la mayor parte de los días, una lucha metafórica. A veces, a partir de las metáforas, irrumpen, lenta o inesperadamente, prácticas transformadoras inéditas. (García Canclini, 1990, p. 326)

Por esto, es importante estar atentos a los espacios, los imaginarios y culturas estéticas que habitan los estudiantes. Estas pueden provenir de los lugares menos creíbles, como lo es la narcocultura. Por eso no debemos estigmatizar y segregar a priori, ya que hacer un reduccionismo impide ver los matices que está produciendo esta cultura.

\section{Propuesta: Modelo rizomático ${ }^{15}$}

La intencionalidad del sistema educativo se contrarresta con la clara intención de los estudiantes de dialogar y comunicarse a través de todas las formas posibles, como las estéticas, para dar a conocer sus intereses, su cultura y como se van construyendo como personas.

Encontramos respuestas a este fenómeno en las teorías de Deleuze y Guattari (2002) acerca de los conceptos de liminalidad e hibridez y su relación con la construcción de saberes en la educación. Se propone un modelo

15 Rizoma: Tallo horizontal y subterráneo; como el del lirio común. (Real academia, 1970) 


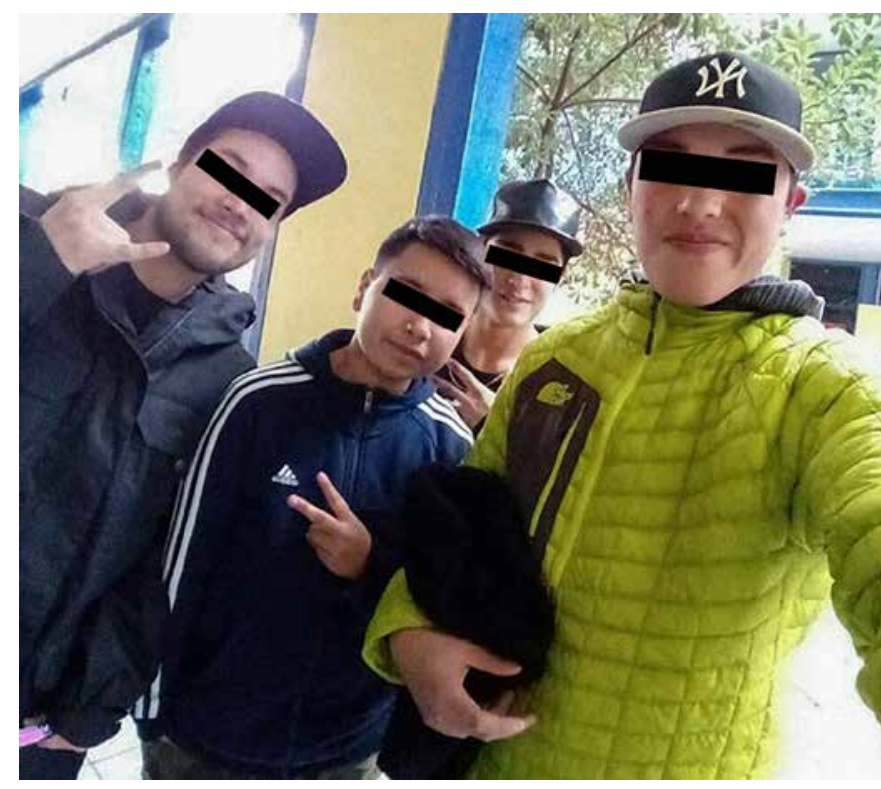

Trabajo de campo (2020). Fotografía: Mario González

rizomático, es decir más flexible y abierto que una educación arbórea lineal y binaria

Contrariamente a los sistemas centrados (incluso policentrados), de comunicación jerárquica y de uniones preestablecidas, el rizoma es un sistema acentrado, no jerárquico y no significante, sin General, sin memoria organizadora o autómata central, definido únicamente por una circulación de estados. (Deleuze y Guattari, 2002: p.26)

Esta es la forma en que las subculturas emergen tomando y rechazando aspectos diferentes de otras culturas. En estos desplazamientos se interesa Canclini, quien nos insta a seguir un camino que recoja esta particularidad de la sociedad actual para apoyar a la educación; rescatando su configuración. El autor nos dice que se debe "seguir construyendo principios teóricos y procedimientos metodológicos que nos ayuden a volver este mundo más traducible, o sea convivible en medio de sus diferencias, y aceptar a la vez lo que cada uno gana y está perdiendo al hibridarse" (García Canclini, 2003; pag.8).

Estos intersticios, nos muestran una dinámica constante de desplazamientos en múltiples direcciones. Lo que se ve en los adolescentes es justamente como se producen y manipulan esta multiplicidad que desafía la hegemonía y se posiciona desde el protagonismo de sus participantes. Es decir, desde sus propias experiencias las cuales generan una identidad cultural propia. Así, este transito esta dado como resistencia a la reproducción, que la sociología de la educación pone en cuestión y de la cual hace un análisis crítico. El sistema capitalista busca colonizar sistemáticamente a toda la sociedad teniendo el control social y psicológico oponiéndose a la emancipación y fomentando el individualismo a través del consumo y deteriorando la cohesión social. El Sociólogo Henry Giroux lo define como:

Los usos del cuerpo, de los lenguajes y del tiempo son todos objetos privilegiados de control, social: innumerables elementos de la educación explícita - para no mencionar la transmisión práctica, mimético- se relacionan con usos del cuerpo ("sentarse bien", "no toques") o usos del lenguaje ("di esto" o "no digas eso"). (Giroux, 1983: p.15)

Como profesores proponemos lo contrario al sistema, es decir construir una sociedad participativa y colaborativa de todos los individuos. Vemos que subterráneamente en los rizomas comienzan a emerger las epistemologías del sur, a través de las letras de la música urbana, que se hace social y política. Además, que fomenta la cohesión de la comunidad y logra descolonizarse del modelo, encontrando formas de desplazamientos de los saberes, las tradiciones, las etnias, los idiomas, en fin. Así, se logra reconstruir la trama social, que se manifiesta a través de lo diverso. De esta manera, se nutren los imaginarios, en este conjunto de interrelaciones que van constituyendo el pensamiento social y colectivo.

\section{Referencias}

Acosta, L. E. (2014). Narcoestética de la acumulación. Multidisciplina. 19.108-124.

Agamben, G. (1995). Homo sacer: El poder soberano y la nuda vida. Valencia: Pre_textos.

De Beauvoir, S. (1949). El segundo sexo. Buenos aires: Siglo veinte.

Bourdieu, P. (1997). Capital cultural, escuela y espacio social. Madrid: Siglo XXI editores.

Bourdieu, P. (1992). Responces . Paris: Seuil.

Buendia, L. \&. (1999). Metodos de Investigacion en Psicopedagogía. Madrid: McGraw-Hill.

Castel, R. (2004). La exclusión: bordeando sus fronteras. Barcelona: Gedisa. 
De Sousa Santos, B. (2017). Epistemologías del Sur. Utopía y Praxis Latinoamericana. 16(54), 17-39.

Deleuze, G. y Guattari, F. (2002). mesetas. Capialismo y esquizofrenia.Valencia: Pre-textos.

Dorlin, E. (2009). Para una epistemologia de las resistencias. Paris: PUF.

Dorlin, E. (2009). Sexo, género y sexualidades. Buenos aires: Nueva visión.

Echeita, G. (2013). Inclusión y exclusión educativa. De nuevo "voz y quebranto".Madrid: REICE.

Etimológico. (2019). Vulnerable. Recuperado de https://tinyurl.com/yvvz46jw

Fajardo, C. F. (2014). Gusto estético en la globalización. Calle 14 revista de investigación en el campo del arte. 9(13). 52-69. Foucault, M. (1966). El cuerpo utópico. Heterotopías. Tucuman: Nueva Visión.

Ganter, R. (2016). Narcocultura y signos de transfronterización en Santiago de Chile. Mitologías hoy. 14.287-302.

García Canclini, N. (2007). ¿Que son los imaginarios y como actúan en la ciudad? Eure, Pontificia Universidad Catolica de Chile. 33(99). 89-99.

García Canclini, N. (1990). Culturas híbridas: Estrategias para entrar y salir de la modernidad. México,D.F.:

Grijalbo.

García Canclini, N. (2003). Noticias recientes sobre hibridación. Trans. Revista Transcultural de Música.7. 1-17.

Giroux, H. (1983). Teorías de la reproducción y la resistencia en la nueva sociología de la educación: un análisis crítico. Harvard Education Review. 15.

Luanko. (2018). Witxapaiñ "Estamos de pie". Chile.

Pardo León, J. A. (2018). Transformaciones estéticas: la narcocultura, la producción de valores culturales y la validación del fenómeno narco. Calle 14 Revista De investigación En El Campo Del Arte, 13(24), 400-409.

Paz, O. (1981). El laberinto de la soledad. Madrid: Fondo de la cultura económica de España.
Portavoz, A. (2013). El otro Chile. Santiago, Chile.

Real academia. (1970). Diccionario de la lengua española. Madrid: Espasa-Calpe, S.A.

Santos, D. (2016). Introducción de lo narco como modelo cultural. Una apropiación transcultural.

Mitologías hoy. 14. 9-23.

SENDA. (2018). Décimo Segundo Estudio Nacional de Drogas. Santiago: Ministerio del Interior y Seguridad Pública.

Strauss, A. \&. (2002). Bases de la investigación cualitativa: técnicas y procedimientos para desarrollar la teoría fundamentada. Medellín: Universidad de Antioquia.

Valenzuela, J. (2014). Jefe de jefes: corridos y narcocultura en México. Revista Austral de Ciencias Sociales. 13. 115-124. 